\title{
ANALISIS EMBOLI PARU MENGGUNAKAN DUAL ENERGY LUNG PERFUSION BLOOD VOLUME CT ANGIOGRAFI PULMONAL PADA PESAWAT DUAL SOURCE CT SCAN
}

\author{
Sherin Himmatus Suroyya ${ }^{1)}$, Kukuh Nurcahyo ${ }^{2)}$, Guntur Winarno ${ }^{3)}$, Shinta Gunawati ${ }^{4)}$ \\ ${ }_{1,2}^{1}$ RSUP Cipto Mangunkusuma Jakarta \\ ${ }^{3.4}$ Poltekkes Kemenkes Jakarta II, Indonesia \\ Corresponding author: Sherin Himmatus Suroyya \\ e-mail: sherinsuroyya1@ gmail.com
}

\begin{abstract}
Background: DECT-based scanning protocol with dual source CT scan, recommended for pulmonary perfusion, the protocol aims to evaluate pulmonary artery and pulmonary perfusion from CT contrast examination.

Purpose: The purpose of this research was to determine how the pulmonary angiography CT scan technique to analyze pulmonary embolism using Dual Energy Lung Perfusion Blood Volume on Dual Source CT Scan.

Methods : This research is a qualitative descriptive with primary data sources, namely CT Scan of Pulmonary Angiography patients with a Pulmonary Embolism Suspect using 128 slice Dual Source Dual Energy Siemens Somatom CT Scan analyzed using PBV Dual Energy Lung using the Region Of Interest (ROI) analysis technique and using material decomposition parameters, from July to October 2020 at National Central General Dr. Cipto Mangunkusumo Jakarta Hospital.

Results: The results obtained were the process from the beginning of the patient registration, which was carried out by CT Pulmonary Angiography examination in the administration until the examination was completed. The CT scan technique for pulmonary angiography was conducted using 128 slice Dual Source Dual Energy Siemens Somatom CT Scan to analyze pulmonary embolism using the post processing Lung Perusion Blood Volume application.

Conclusion : The results of the examination of the patient showed a picture of pulmonary embolism in the superior and inferior branches of the right pulmonary artery, and still visible contrast flow to the distal branch.
\end{abstract}

Keyword : Lung Embolism, CTA Pulmonal, Lung Perfusion Blood Volume, Dual Souce Dual Energy.

\section{Pendahuluan}

Emboli paru merupakan salah satu kegawatdaruratan pada bidang kardiovaskular yang cukup sering terjadi. (Octaviani \& Kurniawan, 2018) Insiden emboli paru sangat tinggi namun penegakan diagnosisnya sangat sulit dikarenakan gejala yang timbul pada setiap pasien sangat bervariasi. (Dinata et al., 2019)

Untuk menegakkan diagnosis emboli paru, perlu ditunjang dengan anamnesa, pemeriksaan fisik, pemeriksaan laboratorium dan imaging. (Octaviani \& Kurniawan, 2018) Multi Detektor
Computed Tomography Pulmonary Angiography adalah modalitas yang paling umum digunakan dalam pemeriksaan yang diduga Emboli Paru. (Goldhaber \& Bounameaux, 2012) (Wiener et al., 2013) CTPA direkomendasikan oleh American College of Radiology untuk evaluasi pasien dengan dugaan emboli paru karena sensitivitas dan spesifisitasnya yang tinggi. (Panels et al., 2017) Angiografi paru merupakan standar baku emas untuk mendiagnosis emboli paru. (Rosyid, 2016)

Diperkenalkan juga Perfusion Blood Volume (PBV) yang merupakan bagian dari CT 
dual-energy. Pencitraan ini dapat menilai perfusi paru.(Rosyid, 2016) Metode ini dapat menjadi alat diagnostik baru untuk evaluasi emboli paru. (Sueyoshi et al., 2011) Menurut Guang Ming Lu dalam jurnal Dual Energy CT of the Lung, satusatunya perangkat lunak yang saat ini tersedia secara komersial untuk perfusi paru berbasis DECT analisis gambar (Syngo DE Lung $P B V$, Siemens Healthcare) adalah bagian perangkat lunak pasca-pemrosesan DECT yang tersedia di Multi Modalitas Syngo (Siemens Healthcare). (Lu et al., 2012) Kemampuan MDCT paru berbasis Dual Energy Computed Tomography untuk secara bersamaan memberikan informasi fungsional dan morfologis memungkinkan evaluasi Pulmonary Embolism (PE). Dibandingkan dengan teknik CT perfusi yang dikembangkan sebelumnya dan dengan teknik CT konvensional untuk pencitraan paru, DECT memungkinkan visualisasi selektif distribusi media kontras dengan resolusi spasial yang tinggi dan tidak ada paparan radiasi tambahan pada pasien. (Gm et al., 2012)(Hidayat, 2013)(Goldhaber \& Bounameaux, 2012) Perkembangan lebih lanjut dalam teknik DECT dan teknologi pemindai CT akan semakin mendorong dan meningkatkan penggunaan aplikasi ini dan membuka jalan baru dalam pencitraan paru. (Alvin C. Silva, MD • Brian G. Morse, MD - Amy K. Hara, MD - Robert G. Paden, MS • Norio Hongo, MD • William Pavlicek, 2011)

Berdasarkan latar belakang tersebut penulis merumuskan permasalahan yaitu, bagaimana teknik pemeriksaan CT Scan Angiografi Pulmonal menggunakan Dual Energy Lung Perfusion Blood Volume pada pesawat Dual Source CT Scan pada kasus emboli paru? Tujuan dari penelitian ini untuk mendeskripsikan teknik pemeriksaan dan menganalisis hasil citra pemeriksaan CT Scan Angiografi Pulmonal menggunakan Dual Energy Lung Perfusion Blood Volume pada pesawat Dual Source CT Scan pada kasus emboli paru.

\section{Metode}

Penelitian ini merupakan penelitian deskriptif kualitatif dengan sumber data primer yaitu pasien yang melakukan CT Scan Angiografi Pulmonal dengan kasus Suspek Emboli Paru menggunakan pesawat CT Scan Siemens Somatom 128 slice
Dual Source Dual Energy yang dianalisis menggunakan Dual Energy Lung PBV dengan menggunakan teknik analisis Region Of Interest (ROI) dan menggunakan parameter dekomposisi material, pada bulan Juli sampai dengan Oktober 2020 di Rumah Sakit Umum Pusat Nasional Dr. Cipto Mangunkusumo Jakarta.

\section{Hasil Dan Pembahasan}

Penelitian telah dilakukan di CT Scan Departemen Radiologi RSUPN Dr. Cipto Mangunkusumo Jakarta. Waktu penelitian dimulai pada bulan Juli sampai dengan Oktober 2020 menggunakan pesawat CT Scan Siemens Somatom 128 slice Dual Source Dual Energy. Penelitian dilakukan pada pasien laki-laki berusia 38 tahun dengan Deep Vein Thrombosis (DVT) kedua kaki sejak 3 minggu, merah dan keras, saat ini sudah sampai perut. Pasien tidak pernah mengalami trauma, operasi, dan sakit lainnya. Pasien sesak nafas sejak 4 hari dan membaik setelah diberikan pengencer darah. Pasien dilakukan pemeriksaan CT Scan Angiografi Pulmonal dengan diagnosa suspek emboli paru.

Alur pemeriksaan CT Scan Angiografi Pulmonal di RSUPN Cipto Mangunkusumo Jakarta dimulai dari pendaftaran pasien dengan membawa surat permintaan radiologi dari dokter pengirim untuk melakukan CT Scan Angiografi Pulmonal dan membawa hasil laboratorium Ureum, Creatinin dan eGFR maksimal satu bulan sebelum pemeriksaan. Nilai eGFR yang disarankan yaitu $\geq 30 \mathrm{ml} / \mathrm{min}$.

Persiapan pasien sebelum pemeriksaan yaitu pasien puasa kurang lebih 4-6 jam sebelum pemeriksaan. Pada saat hari pemeriksaan petugas menyiapkan alat dan perlengkapan yang akan digunakan untuk pemeriksaan seperti: pesawat CT Scan Siemens Somatom 128 slice Dual Source Dual Energy, dual injektor syringe yang berisi kontras media iodine 370 sebanyak $95 \mathrm{ml}$ dan $\mathrm{NaCl}$ 0,9\% sebanyak $40 \mathrm{ml}$, abocath nomor 20, kapas alkohol, stuwing atau pengikat, micropore atau plester, arm support, knee pad, printer dan Digital Versatile Disk - Read Write (DVD-RW). Printer dengan merk Agfa 5320 Laser Image.

Sebelum pemeriksaan, pasien atau keluarga pasien mengisi inform consent dan pasien dianamnesa terlebih dahulu oleh dokter radiologi. Sebelum dilakukan scan, pasien mengganti pakaian dengan pakaian untuk pemeriksaan dan pastikan tidak ada benda yang 
dapat mengganggu hasil gambaran (benda logam) disekitar objek pemeriksaan.

Posisi pasien pada pemeriksaan CT Scan Angiografi Pulmonal yaitu pasien diposisikan tidur telentang (supine) diatas meja pemeriksaan CT Scan dengan posisi feet first. Pasang abocath ukuran 20 di intra vena line lalu sambungkan ke konektor injector yang sudah disiapkan, kemudian lakukan patensi dengan memasukan $\mathrm{NaCl}$ sebanyak $15 \mathrm{ml}$. Tes patensi dilakukan untuk mengecek lancar atau tidaknya akses intravena yang akan dimasukan bahan kontras media. Setelah patensi, posisikan kedua tangan pasien keatas kepala. Atur landmark pada Sternal Notch.

Ambil data pasien yang akan dilakukan pemeriksaan, lengkapi data pasien seperti diagnosa dan berat badan, lalu klik exam. Pilih Protokol Dual Energy, pilih DE_Thorax_Analysis untuk mengerjakan CT Scan Angiografi Pulmonal. Atur parameter kV A 100 ; B Sn 140, quality reff mAs A 44 ; B 40, kolimasi $64 \times 0.6$, rotation time $0.28 \mathrm{~s}$, pitch 0.85 , delayed $3 \mathrm{~s}$. Buat Topogram / Scout / Scanogram area dada AP dan Lateral. Pastikan batas atas pada apex paru dan batas bawah pada lower diafragma di topogram posisi AP tidak terpotong serta batas inferior dan posterior thorax pada topogram posisi lateral tidak terpotong. Buat CT Scan Pre Kontras Thorax pada area tersebut. Selanjutnya atur pre monitoring atau locator setinggi Arteri Pulmonlis, scan dibagian tersebut. Pasang ROI di Arteri Pulmonalis. Atur area Scan Dual Energy Artery pada CT Scan Angiografi Pulmonary. Atur injector siap masuk kontras menggunakan automatic triggering pada titik ROI yang sudah diatur sebelumnya. Pada pasien ini volume kontras media yang dimasukan sebanyak $95 \mathrm{cc}$ dengan flow rate $4 \mathrm{ml} / \mathrm{s}$. Tekan bersama-sama Injector dan tombol Scan. Masuk monitoring, perhatikan kenaikan HU pada titik ROI yang telah diberikan tanda (HU Threshold 100). Jika titik HU sudah mencapai 100 secara otomatis pasien akan diinstruksikan untuk tarik nafas tahan dan secara otomatis scan akan dilakukan. Setelah scan fase arteri selesai, scan akan secara atomatis melanjutkan pengambilan fase vena dengan delay $3 \mathrm{~s}$ dari pengambilan fase arteri. Dan pemeriksaan CT Scan Angiografi Pulmonary selesai dilakukan. Setelah selesai dilakukan pemeriksaan, menunggu selama 30 menit untuk evaluasi kontra indikasi dari penyuntikan kontras media.
Selanjutnya dilakukan perhitungan dengan menggunakan perangkat lunak pascapemrosesan, Perfusion Blood Volume (PBV) yang merupakan CT dual-energy, dapat menilai perfusi paru. Untuk menganalisis emboli paru, set data yang berasal dari CT dual energy dapat digunakan untuk menghasilkan peta yodium yang memungkinkan visualisasi distribusi yodium dalam paru setelah pemberian bahan kontras intravena. Prinsip dasar DECT adalah dekomposisi material berdasarkan perbedaan atenuasi pada tingkat energi yang berbeda. Dengan menggunakan algoritma dekomposisi tiga bahan, dimungkinkan untuk menghasilkan gambar khusus material yang terpisah. Jika substansinya yang menarik adalah yodium dalam parenkim paru, diasumsikan bahwa triplet material yang ideal dibutuhkan untuk diterapkan pada dekompresi tiga bahan yang terdiri dari yodium, udara, dan jaringan lunak. Analisis hasil ditampilkan sebagai multiplanar berkode warna, dimana pembuluh dengan kandungan yodium tinggi diberi kode orange, dan pembuluh yang mengandung bahan tromboemboli diberi kode hitam.

Analisis volume kuantitatif atau analisis Region Of Interest (ROI) dilakukan untuk menilai iodine density dan nilai HU pada daerah yang dicurigai emboli paru. Analisis Lung PBV dengan cara menempatkan ROI yang terdapat di menu evaluation ke titik yang dicurigai emboli paru. Tempatkan titik ROI di daerah hipodens pada area tersebut, eksplorasi hasil dari analisis Lung PBV dengan mengamati nilai iodine density dan nilai HU yang muncul pada titik ROI yang telah ditempatkan.

Tatalaksana penggunaan aplikasi Dual Energy Lung PBV pada kasus Emboli Paru di RSUPN Cipto Mangunkusumo Jakarta yaitu tentukan data yang akan diproses di local database, pilih data Dual Energy potongan tipis 2,0 $\mathrm{mm}$ A dan $\mathrm{B}$, untuk melakukan processing data, pilih menu application, pilih CT lalu pilih Dual Energy. Setelah data masuk ke dalam menu Dual Energy pilih software aplikasi Lung PBV yang akan digunakan, seperti terlihat pada Gambar 1. 

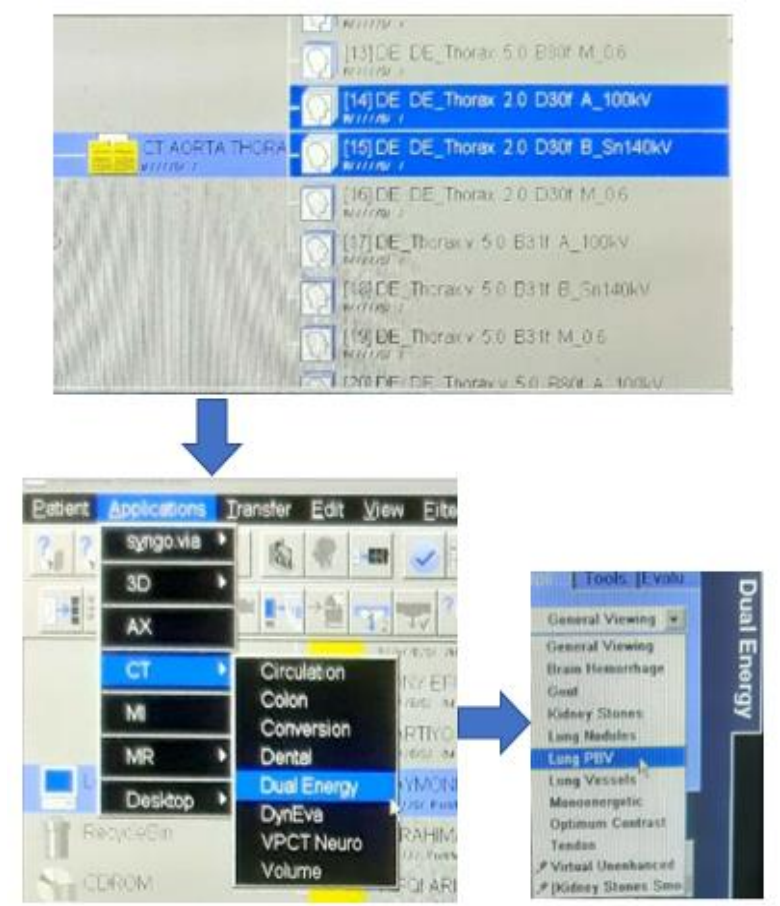

Gambar 1. Menu Lung PBV

Nilai iodine density di titik ROI $\geq=1.89$ $\mathrm{mg} / \mathrm{ml}$, daerah tersebut merupakan parenchim normal. Nilai iodine density $\geq=0.83 \mathrm{mg} / \mathrm{ml}$, daerah tersebut merupakan defect non ocluded yang artinya aliran atau distribusi kontras menurun tapi kemungkinan besar bukan karena adanya emboli. Sedangkan jika nilai iodine density $0.27 \mathrm{mg} / \mathrm{ml}$, daerah tersebut merupakan defect ocluded yang artinya terjadi sumbatan oleh emboli.

Dari hasil pemeriksaan CT Scan Angiografi Pulmonalis terlihat adanya gambaran yang dicurigai emboli paru diarteri pulmonalis kanan cabang superior dan inferior. Dilakukan analisis pengukuran menggunakan perangkat lunak pasca-pemrosesan, Perfusion Blood Volume (PBV) di daerah tersebut pada potongan axial dan coronal. Penelitian pengukuran analisis Lung PBV dengan cara menempatkan ROI di titik emboli dilakukan sebanyak tiga kali pada potongan axial dan coronal untuk mendapatkan validitas data pengukuran. Hasil pengukuran akan menampilkan nilai iodine density dan nilai HU yang dapat menunjukan zat dari daerah yang dicurigai adanya emboli. Dari hasil analisis Lung PBV didapatkan hasil seperti terlihat pada Gambar 2 berikut :

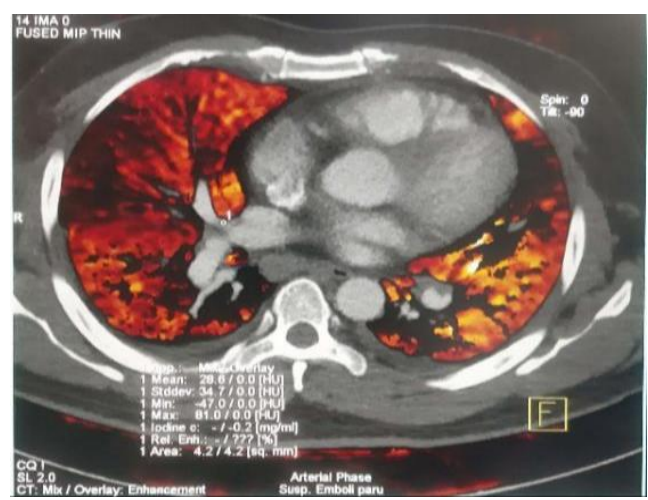

(a)

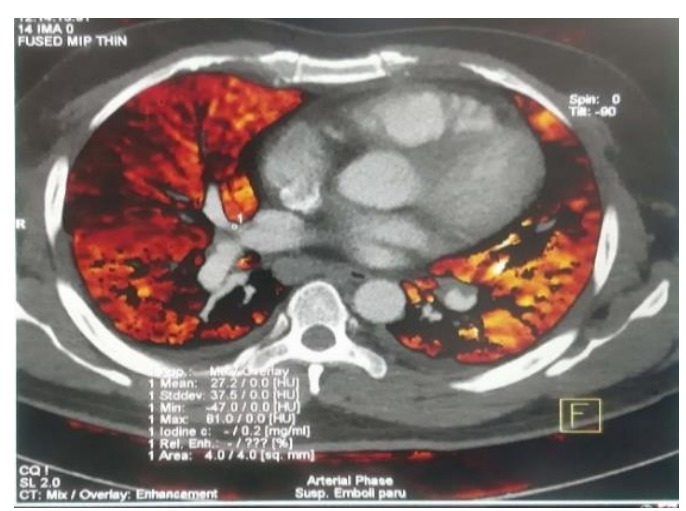

(b)

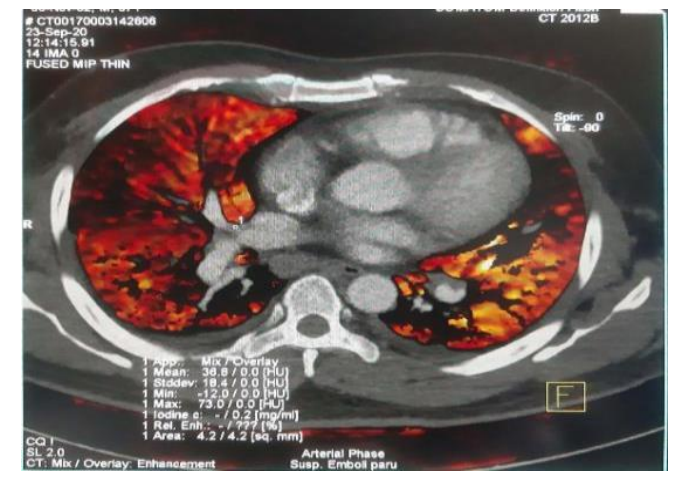

(c)

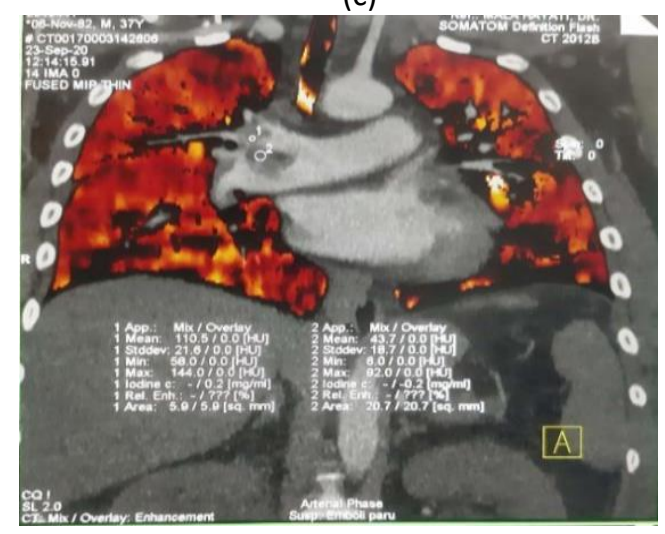

(d) 
(e)

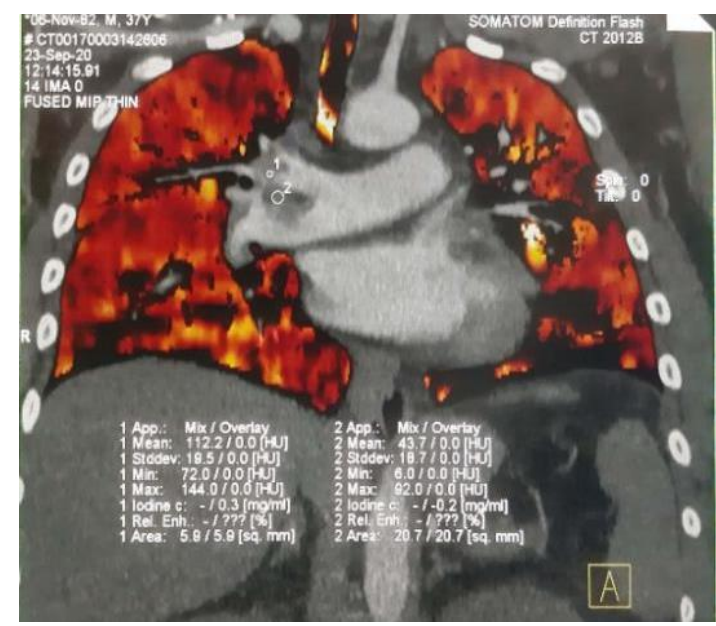

Tabel1. Hasil Perhitungan Lung PBV Arteri Pulmonalis Kanan Superior

\begin{tabular}{cccc} 
Objek & $\begin{array}{c}\text { Nilai iodine } \\
\text { density }\end{array}$ & Nilai HU & $\begin{array}{c}\text { Daerah Curiga } \\
\text { Emboli }\end{array}$ \\
\hline Gambar (a) & $0.2 \mathrm{mg} / \mathrm{ml}$ & $28.6 \mathrm{HU}$ & defect ocluded \\
Gambar (b) & $0.2 \mathrm{mg} / \mathrm{ml}$ & $27.2 \mathrm{HU}$ & defect ocluded \\
Gambar (c) & $0.2 \mathrm{mg} / \mathrm{ml}$ & $36.8 \mathrm{HU}$ & defect ocluded \\
Gambar (d) & $0.2 \mathrm{mg} / \mathrm{ml}$ & $110.5 \mathrm{HU}$ & defect ocluded \\
Gambar (e) & $0.3 \mathrm{mg} / \mathrm{ml}$ & $112.2 \mathrm{HU}$ & defect ocluded \\
Gambar (f) & $0.3 \mathrm{mg} / \mathrm{ml}$ & $98.5 \mathrm{HU}$ & defect ocluded \\
\hline Rata - Rata & $0.23 \mathrm{mg} / \mathrm{ml}$ & $68.98 \mathrm{HU}$ & defect ocluded \\
\hline
\end{tabular}

Sumber : RSUPN dr. Cipto Mangunkusumo Jakarta, 2020

Nilai rata-rata iodine density yang (f)

Gambar 2. Hasil Analisis Lung PBV Arteri

Pulmonalis Kanan Superior (a) perhitungan axial pertama (b) perhitungan axial kedua (c) perhitungan axial ketiga

(d) perhitungan coronal pertama (e) perhitungan coronal kedua (f) perhitungan coronal ketiga (Sumber : RSUPN dr. Cipto Mangunkusumo Jakarta, 2020)

Analisis Lung PBV Arteri Pulmonalis Kanan Superior pada potongan axial dan potongan coronal.

Dari hasil perhitungan pengukuran didaerah yang dicurigai atau daerah suspek emboli paru di arteri pulmonalis kanan superior pada potongan axial dan potongan coronal diperoleh hasil seperti terlihat pada Tabel 1 . 


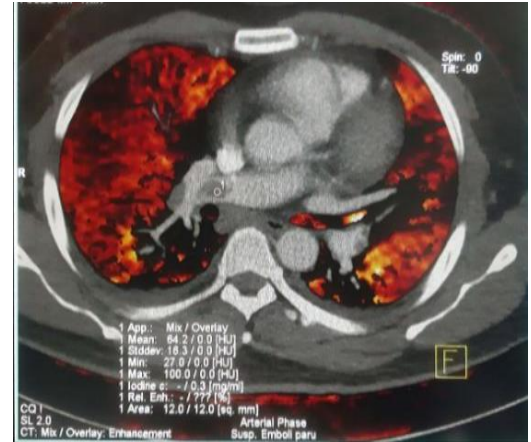

(a)

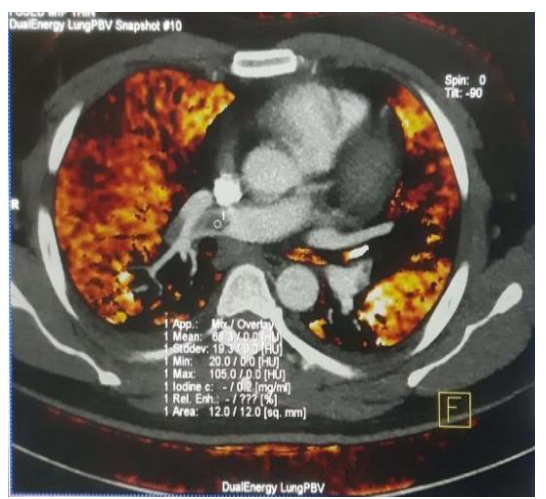

(b)

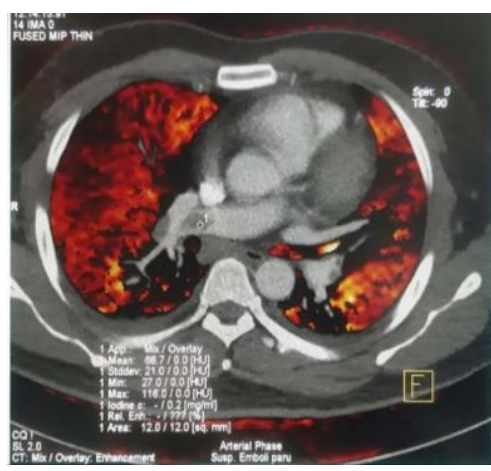

(c)

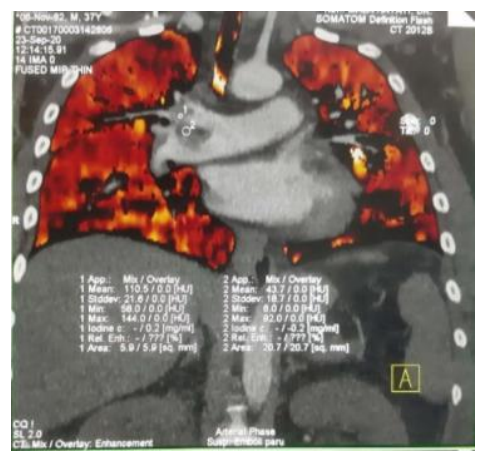

(d)

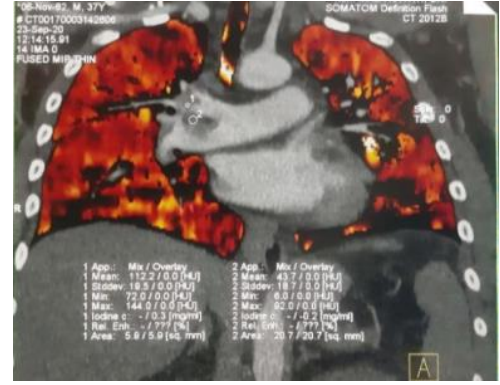

(e)

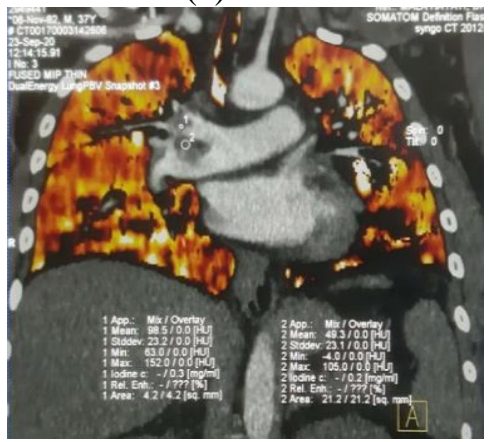

(f)

Gambar 3. Hasil Analisis Lung PBV Arteri

Pulmonalis Kanan Inferior (a) perhitungan axial pertama (b) perhitungan axial kedua (c) perhitungan axial ketiga (d) perhitungan coronal pertama (e) perhitungan coronal kedua (f) perhitungan coronal ketiga

(Sumber : RSUPN dr. Cipto Mangunkusumo Jakarta, 2020)

Dari hasil perhitungan pengukuran didaerah yang dicurigai atau daerah suspek emboli paru di arteri pulmonalis kanan inferior pada potongan axial dan potongan coronal diperoleh hasil seperti terlihat pada Tabel 2

Tabel 2. Hasil Perhitungan Lung PBV Arteri Pulmonalis Kanan Inferior 


\begin{tabular}{|c|c|c|c|}
\hline Objek & $\begin{array}{c}\text { Nilai } \\
\text { iodine } \\
\text { density }\end{array}$ & $\begin{array}{c}\text { Nilai } \\
\boldsymbol{H U}\end{array}$ & $\begin{array}{c}\text { Daerah } \\
\text { Curiga } \\
\text { Emboli }\end{array}$ \\
\hline Gambar (a) & $0.3 \mathrm{mg} / \mathrm{ml}$ & $\begin{array}{l}64.2 \\
\mathrm{HU}\end{array}$ & $\begin{array}{c}\text { defect } \\
\text { ocluded }\end{array}$ \\
\hline Gambar (b) & $0.2 \mathrm{mg} / \mathrm{ml}$ & $\begin{array}{l}68.3 \\
\text { HU }\end{array}$ & $\begin{array}{c}\text { defect } \\
\text { ocluded }\end{array}$ \\
\hline Gambar (c) & $0.2 \mathrm{mg} / \mathrm{ml}$ & $\begin{array}{l}68.7 \\
\mathrm{HU}\end{array}$ & $\begin{array}{c}\text { defect } \\
\text { ocluded }\end{array}$ \\
\hline Gambar (d) & $0.2 \mathrm{mg} / \mathrm{ml}$ & $\begin{array}{l}43.7 \\
\mathrm{HU}\end{array}$ & $\begin{array}{c}\text { defect } \\
\text { ocluded }\end{array}$ \\
\hline Gambar (e) & $0.2 \mathrm{mg} / \mathrm{ml}$ & $\begin{array}{c}43.7 \\
\mathrm{HU}\end{array}$ & $\begin{array}{c}\text { defect } \\
\text { ocluded }\end{array}$ \\
\hline Gambar (f) & $0.2 \mathrm{mg} / \mathrm{ml}$ & $\begin{array}{c}49.3 \\
\mathrm{HU}\end{array}$ & $\begin{array}{c}\text { defect } \\
\text { ocluded }\end{array}$ \\
\hline Rata - Rata & $0.22 \mathrm{mg} / \mathrm{ml}$ & $\begin{array}{c}56.32 \\
\mathrm{HU}\end{array}$ & $\begin{array}{c}\text { defect } \\
\text { ocluded }\end{array}$ \\
\hline
\end{tabular}

Nilai rata-rata iodine density yang didapatkan $0.22 \mathrm{mg} / \mathrm{ml}$. Dapat disimpulkan daerah tersebut merupakan daerah defect ocluded yang berarti terjadi sumbatan karena emboli. Hasil perhitungan pengukuran didaerah yang dicurigai atau daerah suspek emboli paru di arteri pulmonalis kanan inferior potongan axial dan coronal juga diperoleh nilai rata-rata HU 56.32 HU. Dalam tabel nilai HU dapat disimpulkan bahwa daerah tersebut merupakan darah yang bergumpal. Dari perhitungan nilai iodine density dan nilai $\mathrm{HU}$ tersebut, dapat diketahui bahwa daerah yang terdapat pada arteri pulmonalis kanan inferior tersebut merupakan emboli paru.

Pengukuran analisis Lung PBV juga dilakukan di daerah lapangan paru. Hal ini untuk mengevaluasi aliran darah paru pada pasien emboli paru adakah obstruksi karena trombus di daerah lapangan paru. Adapun langkah-langkah pengukuran untuk menghasilkan gambar yang menunjukkan distribusi yodium saja, tidak termasuk struktur mediastinal dan pembuluh paru sentral di parenkim paru, digunakan parameter dekomposisi material untuk pemetaan yodium dalam parenkim paru : $-1000 \mathrm{HU}$ untuk udara di $80 \mathrm{kVp},-1000 \mathrm{HU}$ untuk udara pada $140 \mathrm{kVp}$, $60 \mathrm{HU}$ untuk jaringan lunak pada $80 \mathrm{kVp}$, dan 54 $\mathrm{HU}$ untuk jaringan lunak jaringan pada $140 \mathrm{kVp}$; -960 HU untuk nilai minimum dan $-300 \mathrm{HU}$ untuk nilai maksimum. Hasil gambaran yang dihasilkan akan menggambarkan distribusi yodium dalam parenkim paru saja, gambaran tersebut digunakan untuk melihat aliran darah paru yang menunjukkan homogen perfusi dalam kondisi normal atau tidak, tergantung distribusi yodium di paru.

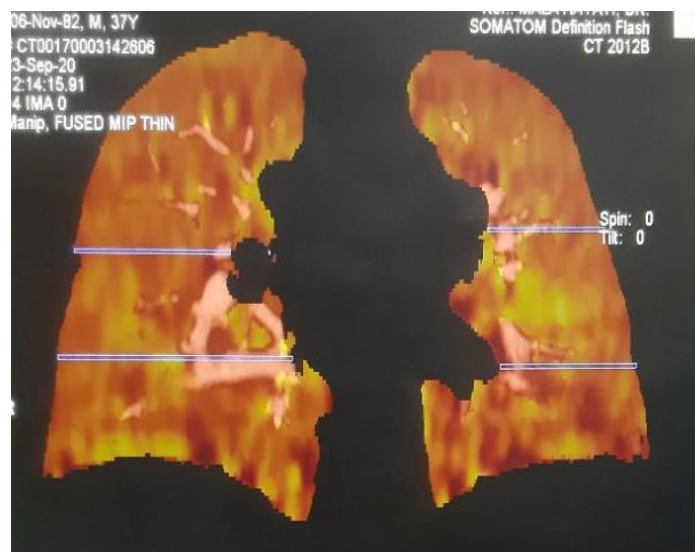

Gambar 4. Hasil Gambaran distribusi kontras di kedua lapangan paru

Dari hasil gambaran tampak menunjukkan homogen perfusi dalam kondisi normal terlihat dari distribusi yodium di kedua lapangan paru. Hal ini menunjukan hasil pemeriksaan CT Scan Angiografi Pulmonary, terdapat gambaran emboli paru diarteri pulmonalis kanan cabang superior dan inferior, dan masih tampak aliran kontras ke cabang distal.

\section{Kesimpulan}

Perangkat lunak pasca-pemrosesan, Perfusion Blood Volume (PBV) dapat menilai perfusi paru. Tahapan analysis Lung $P B V$ dengan cara menempatkan ROI di titik yang dicurigai emboli paru. Hasil dari analysis Lung PBV berupa nilai iodine density dan nilai HU. Dari hasil penelitian di lapangan didapatkan hasil terdapat gambaran emboli paru diarteri pulmonalis kanan cabang superior dan inferior, dan masih tampak aliran kontras ke cabang distal. Dari hasil gambaran kedua lapangan paru menunjukkan homogen perfusi dalam kondisi normal terlihat dari distribusi yodium di kedua lapangan paru.

\section{Daftar Pustaka}

Alvin C. Silva, MD • Brian G. Morse, MD • Amy K. Hara, MD • Robert G. Paden, MS • Norio Hongo, MD • William Pavlicek, P. 
(2011). Dual-Energy ( Spectral ) CT: Applications in $\mathrm{Ab}$ - dominal Imaging 1. RSNA, Vol. 31, N, 1031-1047.

Dinata, D. A., Dian, N., Hariyanto, H., \& Tampubolon, O. (2019). Gagal Napas Sebagai Gejala Awal Emboli Paru Respiratory Failure As An Early Symptom Of Pulmonary Embolism: A Case Report. Journal.Perdatin.Org, Vol 37, No(9), 2934.

Gm, L., Zhao, Y., Lj, Z., \& Uj, S. (2012). DualEnergy CT of the Lung. American Journal of Roentgenology, November, 40-53. https://doi.org/10.2214/AJR.12.9112

Goldhaber, S. Z., \& Bounameaux, H. (2012). Pulmonary embolism and deep vein thrombosis. The Lancet, 379(9828), 1835$1846 . \quad$ https://doi.org/10.1016/S01406736(11)61904-1

Hidayat, E. P. S. et. a. (2013). Teknik CT Scan Dasar. Politeknik Kesehatan Kementerian Kesehatan Jakarta II.

Lu, G. M., Zhao, Y., Zhang, L. J., \& Schoepf, U. J. (2012). Dual-energy CT of the lung. AJR. American Journal of Roentgenology, 199(5 Suppl), 40-53. https://doi.org/10.2214/ajr.12.9112

Octaviani, F., \& Kurniawan, A. (2018). Emboli Paru. Medicinus, 4(9), 313-322. https://doi.org/10.19166/med.v4i9.1191

Panels, E., Imaging, T., Kirsch, J., Brown, R. K. J., Henry, T. S., Javidan-nejad, C., Jokerst, C., Julsrud, P. R., Kanne, J. P., Kramer, C. M., Leipsic, J. A., Panchal, K. K., Ravenel, J. G., Shah, A. B., Mohammed, T. H., Woodard, P. K., \& Abbara, S. (2017). ACR Appropriateness Criteria $\hat{a}$ Acute Chest Pain - Suspected Pulmonary Embolism. Journal of the American College of Radiology, $\quad$ 14(5), $\quad$ S2-S12. https://doi.org/10.1016/j.jacr.2017.02.027

Rosyid, A. N. (2016). Peran pencitraan dalam diagnosis Emboli paru Peran pencitraan dalam diagnosis Emboli paru. February 2013.

Sueyoshi, E., Tsutsui, S., Hayashida, T., Ashizawa, K., Sakamoto, I., \& Uetani, M. (2011). Quantification of lung perfusion blood volume (lung PBV) by dual-energy $\mathrm{CT}$ in patients with and without pulmonary embolism: Preliminary results. European Journal of Radiology, 80(3), e505-e509. https://doi.org/10.1016/j.ejrad.2010.10.011
Wiener, R. S., Schwartz, L. M., \& Woloshin, S. (2013). When a test is too good: How CT pulmonary angiograms find pulmonary emboli that do not need to be found. BMJ (Online), 347(7915), 1-7. https://doi.org/10.1136/bmj.f3368 